disease 2016 Inflammatory Bowel Disease: Global view. World J Gastroenterol 2016; 22: 5655-5667.

6. Kandiel A, Fraser AG, Korelitz B I, Brensinger C, Lewis $J$ D. Increased risk of lymphoma among inflammatory bowel disease patients treated with azathioprine and 6-mercaptopurine. Gut 2005; 54: 1121-1125.

\section{DOI: 10.1038/sj.bdj.2017.9}

\section{OMFS}

\section{Fortitude and dedication}

Sir, to respond to the concerns in Ms Ahmed's letter regarding a lack of women ${ }^{1}$ in OMFS, our department has a female oral and maxillofacial consultant and a female oral surgery associate specialist. As a dental core trainee, I have found it inspiring to work with these women in addition to their male colleagues who have pursued successful careers. As a result of attending conferences and speaking to women in these fields it is clear there is the opportunity to follow these career pathways. Forging any specialist career regardless of gender requires fortitude and dedication and we need to remember this. Indeed many female oral and maxillofacial surgery consultants have successfully pursued this career in addition to having a family.
In medicine, women currently make up $45.4 \%$ of the workforce but only represent $33.5 \%$ of those on the specialist registers. ${ }^{2}$ However, they make up more than half of the specialists in paediatrics and obstetrics and gynaecology. ${ }^{3}$ In dentistry women represent $46.8 \%$ of dental registrants but only $39.8 \%$ of those on specialist lists and only $27.9 \%$ of specialists in oral surgery. ${ }^{4}$ The new junior doctor contract has been cited by some trainees as negatively impacting on their decision to pursue a career in oral and maxillofacial surgery, ${ }^{5}$ and it will be of great interest to see if this change has an effect on the uptake of surgical specialties by women.

To improve Ms Ahmed's understanding of the opportunities available, we would encourage her to attend conferences such as the British Association of Oral and Maxillofacial Surgeons and British Association of Oral Surgeons to meet and learn from the diverse mix of consultants and trainees. Furthermore, in addition to WinS (Women in Surgery), the Medical Women's Federation offer advice, support and mentorship to female trainees. Female trainees establishing such links will facilitate positive female role modelling. It is important that in order to break through the perceived glass ceiling, women must be encouraged and supported not only by their medical colleagues but once appointed as consultants by the organisational hierarchy within which they operate. Society in general must appreciate that the training received and opportunity to progress must be equivalent regardless of gender.

C. Wilson, L. Fryer, by email

1. Ahmed A. OMFS: Gender imbalance? Br Dent J 2016; 221: 372.

2. General Medical Council. List of registered medical practitioners - statistics. Available at: http://www. gmc-uk.org/doctors/register/search_stats.asp (accessed November 2016).

3. General Medical Council. The state of medical education and practice in the UK: 2016. Available at: http://www. gmc-uk.org/publications/somep2016.asp (accessed November 2016).

4. General Dental Council. Registrant report October 2015 Available at: http://www.gdc-uk.org/Newsandpublications/factsandfigures/Documents/Facts $\% 20$ and $\% 20$ Figures $\% 20$ from $\% 20$ the $\% 20$ GDC $\% 20$ register $\% 20$ October\%202015.pdf (accessed November 2016).

5. Herbert C, Kent S, Magennis P, Cleland J. What causes trainees to leave oral and maxillofacial surgery? A questionnaire survey. Br J Oral Maxillofac Surg 2016; doi: 10.1016/j.bjoms.2016.08.023 [epub ahead of print].

DOI: 10.1038/sj.bdj.2017.10 